\title{
Enhanced NMDA Receptor-Mediated Synaptic Transmission, Enhanced Long-Term Potentiation, and Impaired Learning and Memory in Mice Lacking IRSp53
}

\author{
Myoung-Hwan Kim, ${ }^{1 *}$ Jeonghoon Choi, ${ }^{1 *}$ Jinhee Yang, ${ }^{1 *}$ Woosuk Chung, ${ }^{1 *}$ Ji-Hyun Kim, ${ }^{2}$ Sang Kyoo Paik, ${ }^{3}$ \\ Karam Kim, ${ }^{1}$ Seungnam Han, ${ }^{1}$ Hyejung Won, ${ }^{1}$ Young-Soo Bae, ${ }^{1}$ Suk-Hee Cho, ${ }^{2}$ Jinsoo Seo, ${ }^{2}$ Yong Chul Bae, ${ }^{3}$ \\ Se-Young Choi, ${ }^{2}$ and Eunjoon Kim ${ }^{1}$ \\ ${ }^{1}$ National Creative Research Initiative Center for Synaptogenesis and Department of Biological Sciences, Korea Advanced Institute of Science and \\ Technology, Daejeon 305-701, Korea, ${ }^{2}$ Department of Physiology, College of Dentistry and Dental Research Institute, BK21 Program, Seoul National \\ University, Seoul 110-749, Korea, and ${ }^{3}$ Department of Anatomy and Neurobiology, BK21, School of Dentistry, Kyungpook National University, Daegu 700- \\ 412, Korea
}

IRSp53 is an adaptor protein that acts downstream of Rac and Cdc42 small GTPases and is implicated in the regulation of membrane deformation and actin filament assembly. In neurons, IRSp53 is an abundant postsynaptic protein and regulates actin-rich dendritic spines; however, its in vivo functions have not been explored. We characterized transgenic mice deficient of IRSp53 expression. Unexpectedly, IRSp53 $3^{-1-}$ neurons do not show significant changes in the density and ultrastructural morphologies of dendritic spines. Instead, IRSp53 $3^{-I-}$ neurons exhibit reduced AMPA/NMDA ratio of excitatory synaptic transmission and a selective increase in NMDA but not AMPA receptor-mediated transmission. IRSp53 ${ }^{-I-}$ hippocampal slices show a markedly enhanced long-term potentiation (LTP) with no changes in long-term depression. LTP-inducing theta burst stimulation enhances NMDA receptor-mediated transmission. Spatial learning and novel object recognition are impaired in IRSp53 ${ }^{-1-}$ mice. These results suggest that IRSp53 is involved in the regulation of NMDA receptor-mediated excitatory synaptic transmission, LTP, and learning and memory behaviors.

Key words: IRSp53; PSD-95; synapse; actin; LTP; learning and memory

\section{Introduction}

The molecular assembly of synaptic proteins is thought to play important roles in the formation, maturation, and plasticity of neuronal synapses (Scannevin and Huganir, 2000; Funke et al., 2005; Waites et al., 2005; Tada and Sheng, 2006; Craig and Kang, 2007; Okabe, 2007; Sheng and Hoogenraad, 2007). Insulin receptor tyrosine kinase substrate of $53 \mathrm{kDa}$ (IRSp53) is one of the most abundant components of the postsynaptic density (PSD) (Cheng et al., 2006), which represents postsynaptic multiprotein complexes containing membrane, signaling, and scaffolding proteins (Kennedy, 2000).

IRSp53 contains several domains for protein-protein interactions: IRSp53 and missing in metastasis homology domain (IMD), Cdc42/Rac interactive-binding (CRIB), SH3, and postsynaptic density-95/Discs large/zona occludens-1 (PDZ)

\footnotetext{
Received Sept. 9, 2008; revised Jan. 5, 2009; accepted Jan. 6, 2009.

This work was supported by the Creative Research Initiatives Program (E.K.), Korea Research Foundation Grant KRF-2006-312-C00360 (S.-Y.C.), and the Medical Research Center program of the Korea Science and Engineering Foundation (R13-2008-009-01000-0) (Y.C.B.) of the Korean Ministry of Education, Science, and Technology. We thank Dr. Chul Hoon Kim for help with the generation of GluR1 and GluR2 antibodies.

${ }^{*}$ M.-H.K., J.C., J.Y., and W.C. contributed equally to this work.

Correspondence should be addressed to Eunjoon Kim, Department of Biological Sciences, Korea Advanced Institute of Science and Technology, Daejeon 305-701, Korea. E-mail: kime@kaist.ac.kr. DOI:10.1523/JNEUROSCI.4306-08.2009

Copyright $\odot 2009$ Society for Neuroscience $\quad$ 0270-6474/09/291586-10\$15.00/0
}

domain-binding domains (Scita et al., 2008). The IMD (Nterminal 250 aa) of IRSp53, originally known to bind Rac (Miki et al., 2000), forms a zeppelin-shaped dimer (Millard et al., 2005) and bundles actin filaments (Yamagishi et al., 2004). The IMD, also known as I-BAR (inverse-Bin-Amphiphysins-Rvs) domain (Habermann, 2004; Millard et al., 2005; Mattila et al., 2007), binds to and induces the protrusion of membrane in a Racdependent manner (Suetsugu et al., 2006b; Mattila et al., 2007). The CRIB domain binds Cdc42 (Govind et al., 2001; Krugmann et al., 2001), and the SH3 domain interacts with proteins including Shank (a postsynaptic scaffolding protein), DRPLA (a protein associated with dentatorubral-pallidoluysian atrophy), and various actin regulatory proteins such as WAVE2, N-WASP (neural Wiskott-Aldrich syndrome protein), Mena, Eps8, and espin (Miki et al., 2000; Krugmann et al., 2001; Sekerková et al., 2003; Lim et al., 2008; Scita et al., 2008). The C-terminal PDZ-binding motif interacts with PSD-95, an abundant postsynaptic scaffold, and MALS/LIN-7/Veli (Hori et al., 2003; Soltau et al., 2004; Choi et al., 2005). IRSp53 regulates Rac-dependent lamellipodia formation, by promoting WAVE2-mediated regulation of the Arp2/3 actin-nucleating complex and F-actin polymerization (Miki et al., 2000; Nakagawa et al., 2003; Suetsugu et al., 2006a; Abou-Kheir et al., 2008). IRSp53 also regulates Cdc42-dependent filopodia formation through Mena and Eps8 (Miki et al., 2000; Govind et al., 2001; Krugmann et al., 2001; Disanza et al., 2006). 


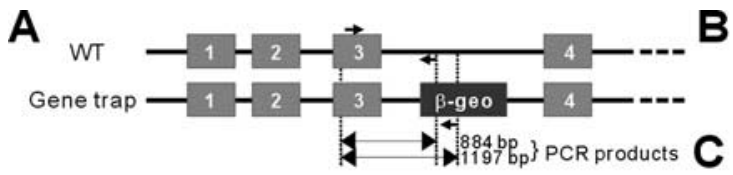

B

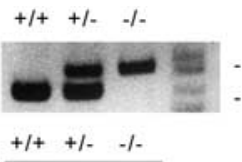

$1197 \mathrm{bp}(\mathrm{KO})$ 884 bp (WT)

Whole

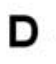

brain
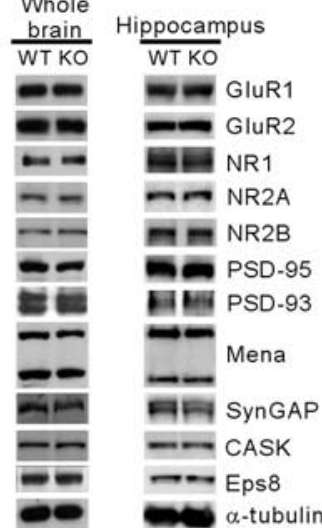

\section{E}
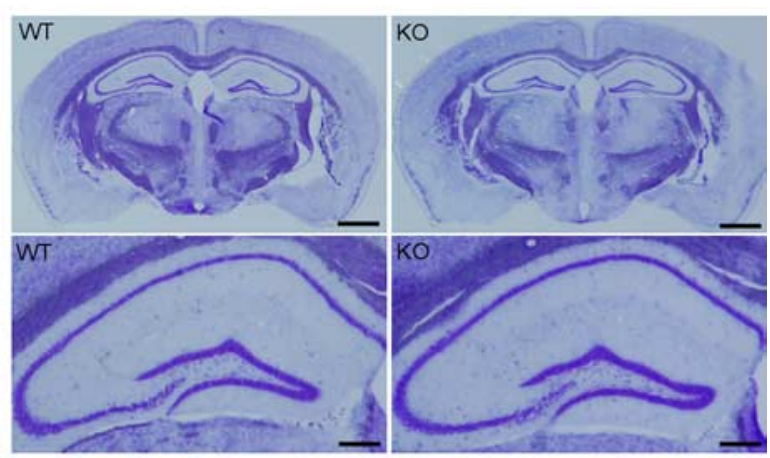

Figure 1. Generation and characterization of IRSp53 $3^{-1-}$ mice.A, Diagram depicting the structure of the IRSp53 gene harboring exons and introns, and the insertion site of the genetrap in the intron between exons 3 and $4 . \boldsymbol{B}$, Identification of the trapped IRSp53 gene by PCR genotyping. C, Undetectable expression of IRSp53 proteins in IRSp53 ${ }^{-/-}$mice. Total brain homogenates from WT, IRSp53 ${ }^{+/-}$, and IRSp53 ${ }^{-1-}$ mice (4 weeks) were immunoblotted with IRSp53 antibodies. D, Unchanged expression levels of other synaptic proteins and IRSp53-interacting proteins (PSD-95, Mena, and Eps8) in whole brain and hippocampal extracts of IRSp53 ${ }^{-1-}$ mice. E, Normal gross morphology of IRSp53 ${ }^{-1-}$ brain (7 weeks) revealed by Nissl staining. Scale bars: top; $150 \mu \mathrm{m}$; bottom, $40 \mu \mathrm{m}$. et al., 2002; Soltau et al., 2002; Choi et al., 2005). IRSp53 rapidly translocates to dendritic spines by NMDA receptor activation (Hori et al., 2005) and regulates spine density and morphology (Choi et al., 2005). However, in view of diverse protein interactions of IRSp53 and its functional regulation of membrane/actin, neuronal functions of IRSp53 need to be further studied.

Here, we report characterization of transgenic mice deficient of IRSp53. Our data suggest novel involvements of IRSp53 in the regulation of NMDA receptormediated excitatory synaptic transmission, long-term potentiation (LTP), and learning and memory behaviors.

\section{Materials and Methods}

Generation of IRSp53 ${ }^{-/-}$mice. A mouse ES cell clone, derived from the 129 ola strain, containing a gene trap insertion in the IRSp53 gene (XG757) was obtained from BayGenomics. The gene trap cassette contained the En2 (Engrailed-2) splice acceptor upstream of the $\beta$-geo (lacZ-neomycin) gene and a polyadenylation signal. Cultured ES cells were microin-
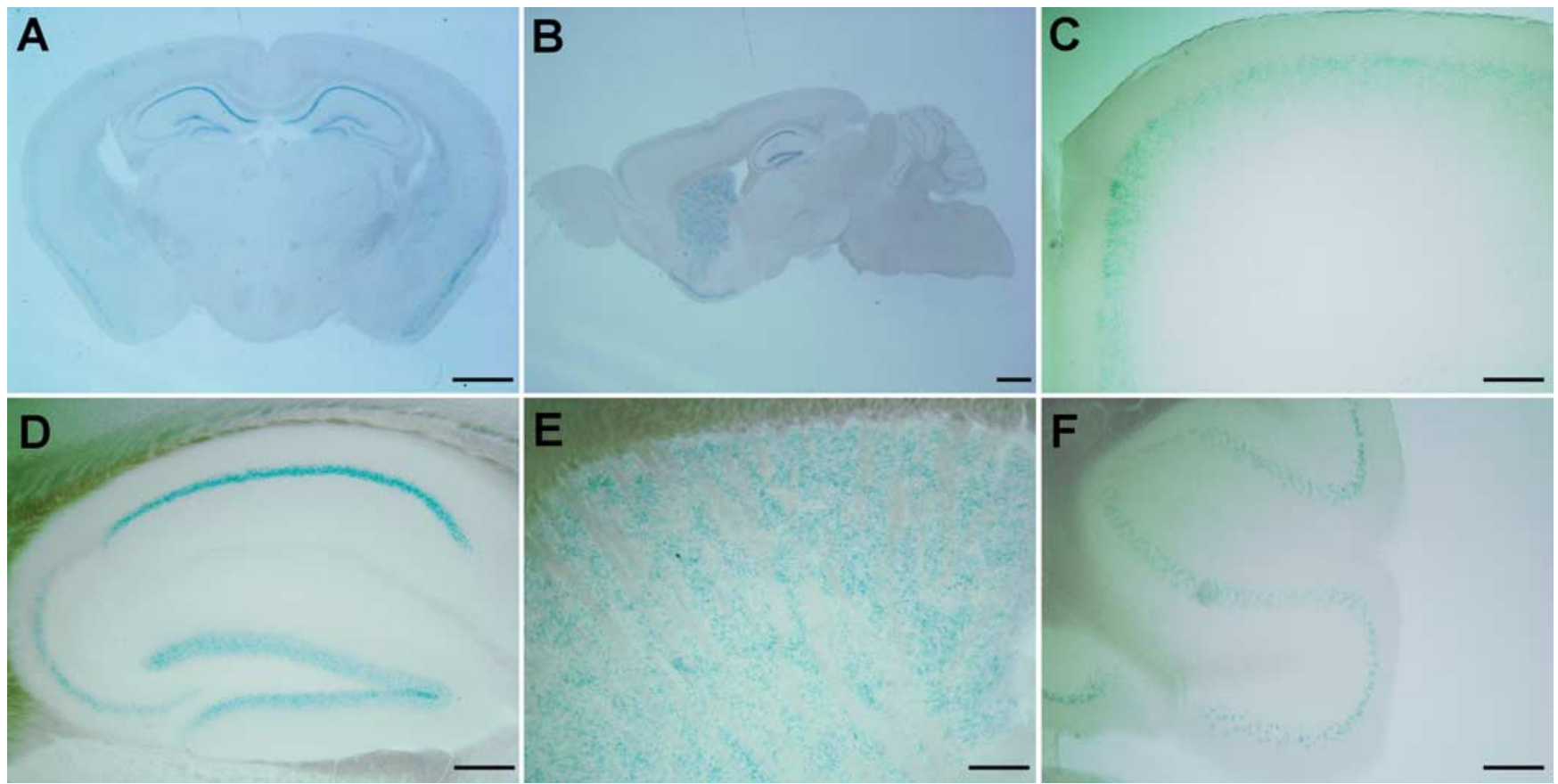

Figure 2. Expression patterns of IRSp53 proteins revealed by X-gal staining of IRSp53 ${ }^{+/-}$brain slices. Coronal $(\boldsymbol{A})$ and sagittal $(\boldsymbol{B})$ brain slices from IRSp53 ${ }^{+/-}$mice $(8$ weeks) were incubated with X-gal to visualize brain regions expressing IRSp53- $\beta$-geo fusion proteins. Brain regions with relatively high IRSp53- $\beta$-geo expression include the cortex (C), hippocampus (D), striatum (E), and cerebellum $(\boldsymbol{F})$. Scale bars: $\boldsymbol{A}, \boldsymbol{B}, 150 \mu \mathrm{m} ; \boldsymbol{C}-\boldsymbol{F}, 30 \mu \mathrm{m}$.

Contrary to non-neuronal functions of IRSp53, its neuronal functions have been less extensively explored, despite its abundant expression in the brain (Cheng et al., 2006) and excitatory synaptic localization (Abbott et al., 1999; Bockmann et al., 2002; Choi et al., 2005). IRSp53 regulates neurite outgrowth in neuroblastoma cells (Govind et al., 2001). IRSp53 interacts with both PSD-95 and Shank, suggesting that IRSp53 links PSD-95 with Shank to promote PSD assembly (Abbott et al., 1999; Bockmann jected into blastocysts and transferred into pseudopregnant C57BL/6J females to generate male chimeras. Chimeras were bred with C57BL/6J females to generate germ line transmitted animals. These mice were crossed with C57BL/6J for five generations before we used them in analyses. The site of cassette insertion in the intron between exons 3 and 4 of the IRSp53 gene was determined by PCR analysis. Genotyping of the mice was performed using PCR and the following three primers: $5^{\prime}$ CACCTTCGCTGCCAAAGGCTA-3' and either 5'-GCACATCT- 


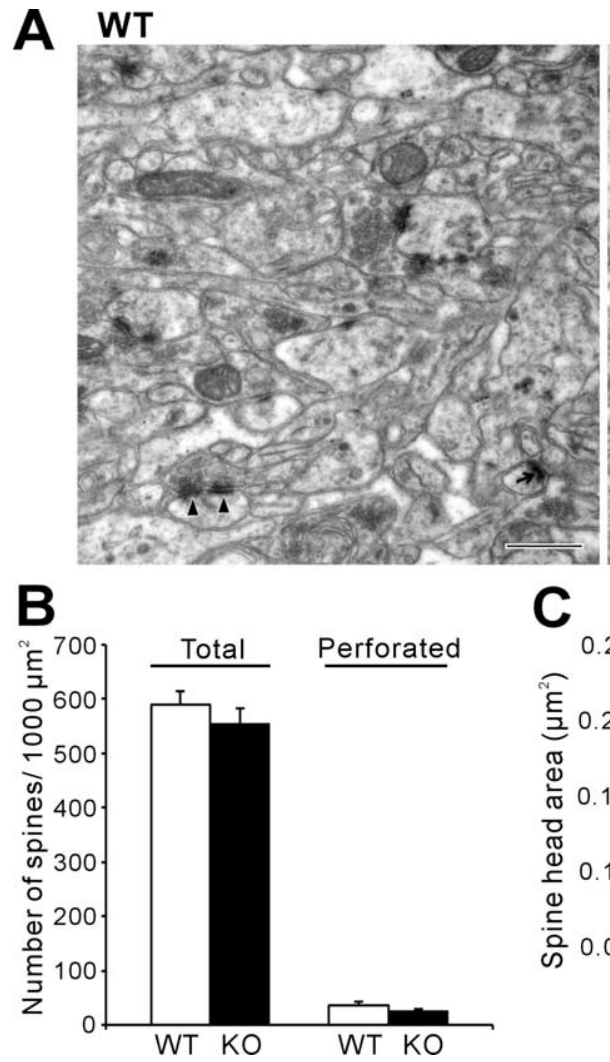

KO

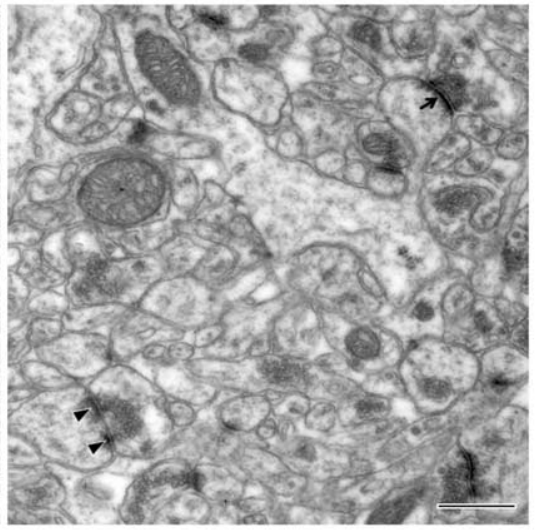

C

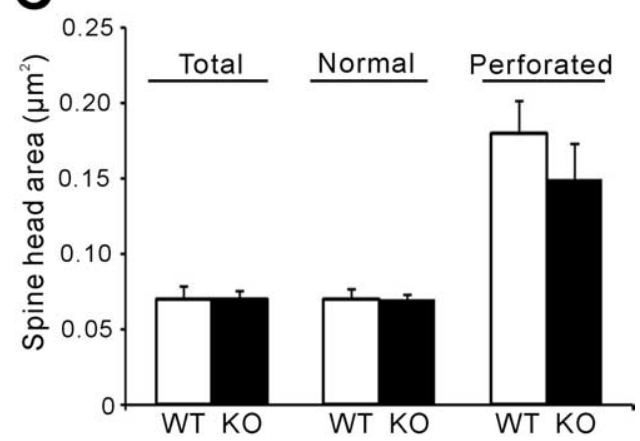

Figure 3. Normal spine density and ultrastructure in IRSp53 $3^{-1-}$ CA1 pyramidal neurons. $A$, Representative electron micrographs of the stratum radiatum of the hippocampal CA1 region from WT and IRSp53 ${ }^{-1-}$ mice (4 weeks). Normal and perforated PSDs are indicated by arrow and arrowheads, respectively. Scale bar, $0.5 \mu \mathrm{m} . \boldsymbol{B}$, Quantitative analysis of the density of total and perforated spines. Bar graph represents mean \pm SEM (total area of the brain region analyzed, $943 \mu \mathrm{m}^{2}$ per mouse; $n=3$ mice for each genotype). C, Head area of dendritic spines (total, normal/nonperforated, and perforated). Bar graph represents mean \pm SEM (total number of spines analyzed, 1648 for WT and 1535 for K0; $n=3$ ).

ACCCGGGGACC-3' [wild type (WT)] or 5'-AGTATCGGCCTCAGGAAGATCG-3' ( $\beta$-geo). The size of the PCR products for the WT and transgene were 884 and $1197 \mathrm{bp}$, respectively.

Antibodies. Rabbit polyclonal PSD-93/chapsyn-110 (1634), SynGAP (1682), and calcium/calmodulin-dependent serine kinase (CASK) (1640) antibodies were generated using glutathione $S$-transferase (GST)PSD-93 (full length; rat), GST-SynGAP (amino acids 1114-1293; rat), and GST-CASK (amino acids 317-479; rat). Guinea pig polyclonal Mena (1683) antibodies were generated using GST-Mena (amino acids 1-275; mouse). Rabbit polyclonal GluR1 (1193) and GluR2 (1195) antibodies were raised using C-terminal peptides of rat GluR1 (SHSSGMPLGATGL) and rat GluR2 (EGYNVYGIESVKI), respectively. The following antibodies have been described previously: IRSp53 and PSD-95 (SM55) (Choi et al., 2005) and NR2B (21266) (Sheng et al., 1994). The following antibodies were purchased commercially: NR1 (BD Biosciences Transduction Laboratories), NR2A (Zymed), $\alpha$-tubulin (Sigma-Aldrich), and Eps8 (BD Biosciences).

Cresyl violet and $X$-gal staining. For cresyl violet staining, mice were transcardially perfused with $4 \%$ formaldehyde in PBS and postfixed at $4^{\circ} \mathrm{C}$ for overnight. After fixation, brains were stored in $30 \%$ sucrose solution for $24 \mathrm{~h}$. For cryosectioning, brains were frozen and sectioned using a cryostat. The $30-\mu \mathrm{m}$-thick brain sections were dipped continuously in $95 \%$ ethanol (15 min), 70\% ethanol ( $1 \mathrm{~min}), 50 \%$ ethanol (1 $\mathrm{min})$, distilled water ( $2 \mathrm{~min})$, distilled water (1 $\mathrm{min})$, cresyl violet staining solution $(0.5 \%$; $1.5 \mathrm{~min})$, distilled water ( $1 \mathrm{~min}), 50 \%$ ethanol ( $1 \mathrm{~min})$, $70 \%$ ethanol ( $2 \mathrm{~min}), 95 \%$ ethanol ( $2 \mathrm{~min}), 100 \%$ ethanol ( $1 \mathrm{~min})$, and xylene (5 min). For X-gal staining, mice brain sections $(50 \mu \mathrm{m})$ were sectioned with vibratome and incubated in X-gal staining solution [PBS, $5 \mathrm{~mm} \mathrm{~K}_{3} \mathrm{Fe}(\mathrm{CN})_{6}, 5 \mathrm{~mm} \mathrm{~K}{ }_{4} \mathrm{Fe}(\mathrm{CN})_{6}, 2 \mathrm{~mm} \mathrm{MgCl}_{2}, 0.01 \%$ deoxycholate, $0.02 \% \mathrm{NP}-40,1 \mathrm{mg} / \mathrm{ml} \mathrm{X}$-gal] at $37^{\circ} \mathrm{C}$ for overnight.
Electron microscopy. Four-week-old male mice were deeply anesthetized with sodium pentobarbital $(80 \mathrm{mg} / \mathrm{kg}$, i.p. $)$ and were intracardially perfused with $100 \mathrm{ml}$ of heparinized normal saline, followed by $500 \mathrm{ml}$ of a freshly prepared fixative of $2.5 \%$ glutaraldehyde and $4 \%$ paraformaldehyde in $0.1 \mathrm{M}$ phosphate buffer, $\mathrm{pH}$ 7.4. Hippocampus was removed from the whole brain and sectioned with Vibratome at $100 \mu \mathrm{m}$ thickness. The sections were postfixed in the same fixative for $2 \mathrm{~h}$, osmicated with $1 \%$ osmium tetroxide in $0.1 \mathrm{~m}$ phosphate buffer for $1 \mathrm{~h}$, dehydrated in graded alcohols, flat embedded in Durcupan ACM (Fluka), and cured for $48 \mathrm{~h}$ at $60^{\circ} \mathrm{C}$. Small pieces containing CA1 stratum radiatum $(\sim 150 \mu \mathrm{m}$ from CA1 pyramidal cell body layer) were cut out of the wafers and glued onto the plastic block by cyanoacrylate. Ultrathin sections were cut and mounted on Formvar-coated single slot grids, stained with uranyl acetate and lead citrate, and examined with an electron microscope (Hitachi $\mathrm{H}-7500$; Hitachi) at $80 \mathrm{kV}$ accelerating voltage. Randomly selected neuropil areas within $120-$ $150 \mu \mathrm{m}$ from cell body were photomicrographed at a $40,000 \times$. Digital images were captured with GATAN DigitalMicrograph software driving a CCD camera (SC1000 Orius; Gatan) and saved as TIFF files. Brightness and contrast of the images were adjusted in Adobe Photoshop 7.0 (Adobe Systems). Sixty micrographs representing $943 \mu \mathrm{m}^{2}$ neuropil regions in each mouse were analyzed and used for quantification. Number of spines, proportion of perforated spines, cross-sectional area of spine head, and PSD length from three WT and IRSp53 $3^{-1-}$ mice were quantified. The measurements were all performed by an experimenter blind to the genotype.

Preparation of hippocampal slices. Transverse hippocampal slices (400 $\mu \mathrm{m}$ thick) from WT and IRSp $53^{-1-}$ mice were prepared using a vibratome in ice-cold dissection buffer (in mM: 213 sucrose, $26 \mathrm{NaHCO}_{3}, 2.5 \mathrm{KCl}, 1.25 \mathrm{NaH}_{2} \mathrm{PO}_{4}, 10$ D-glucose, $2 \mathrm{Na}$ pyruvate, $1.3 \mathrm{Na}$-ascorbate, $3.5 \mathrm{MgCl}_{2}, 0.5 \mathrm{CaCl}_{2}$ bubbled with $95 \%$ $\mathrm{O}_{2} / 5 \% \mathrm{CO}_{2}$ ). The slices were recovered at $36^{\circ} \mathrm{C}$ for $1 \mathrm{~h}$ in normal artificial CSF (ACSF) (in mm: $125 \mathrm{NaCl}, 26 \mathrm{NaHCO}_{3}, 2.5 \mathrm{KCl}, 1.25 \mathrm{NaH}_{2} \mathrm{PO}_{4}, 10$ D-glucose, $1.3 \mathrm{MgCl}_{2}, 2.5 \mathrm{CaCl}_{2}$ ) and thereafter maintained at room temperature.

Electrophysiology. Whole-cell patch-clamp recordings of hippocampal CA1 pyramidal neurons were made using a MultiClamp 700B amplifier (Molecular Devices) under visual control with differential interference contrast illumination in an upright microscope (BX50WI; Olympus). Signals were filtered at $2.8 \mathrm{kHz}$ and digitized at $10 \mathrm{kHz}$. During whole-cell recording, series resistance was monitored each sweep by measuring the peak amplitude of the capacitance current in response to short hyperpolarizing step pulse $(5 \mathrm{mV}, 40 \mathrm{~ms})$. Somatic whole-cell recording of miniature EPSCs (mEPSCs) were obtained at a holding potential of $-60 \mathrm{mV}$ using patch electrodes $(2-3 \mathrm{M} \Omega$ ) filled with a solution containing the following (in mM): $100 \mathrm{CsMeSO}_{4}, 10 \mathrm{TEA}-\mathrm{Cl}$ (tetraethylammonium chloride), $8 \mathrm{NaCl}, 10$ HEPES, 5 QX-314-Cl [N-2(2,6-dimethylphenylcarbamoylmethyl)triethylammonium chloride], 2 Mg-ATP, 0.3 Na-GTP, 10 EGTA, with pH 7.25, 290 mOsm. TTX (1 $\mu \mathrm{M})$ and bicuculline $(20 \mu \mathrm{M})$ were added to ACSF to inhibit spontaneous action potential-mediated synaptic currents and IPSCs, respectively. For NMDA receptor (NMDAR)-mediated mEPSC recordings, $\mathrm{CaCl}_{2}$ and $\mathrm{MgCl}_{2}$ in ACSF were replaced with $\mathrm{SrCl}_{2}$ (4 mM), and 2,3-dihydroxy-6nitro-7-sulfamoylbenzo[f]quinoxaline (NBQX) $(10 \mu \mathrm{M})$ was added to inhibit AMPA receptor-mediated currents. The averaged mEPSC amplitudes from individual cells were used to obtain the mean amplitude. For 

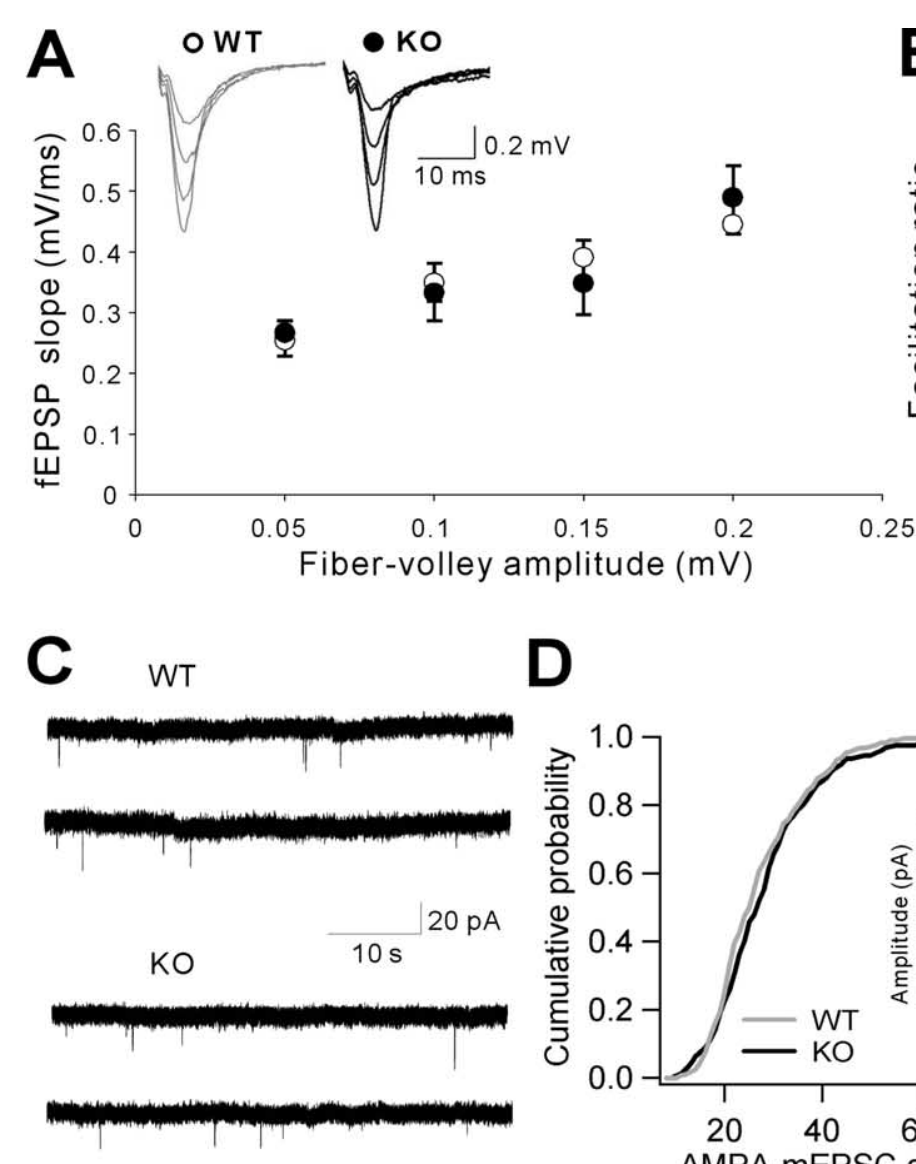

B

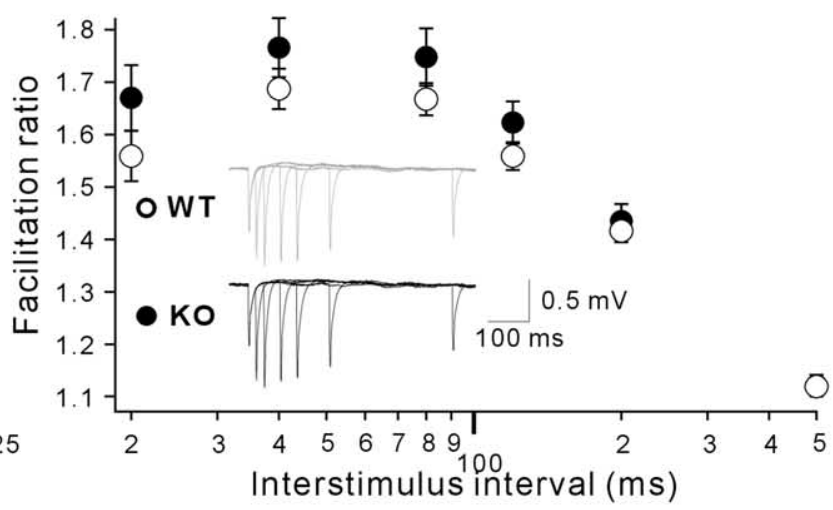

D

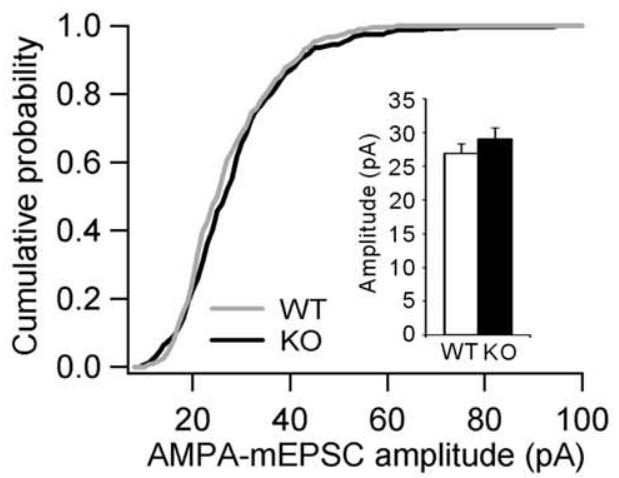

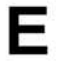

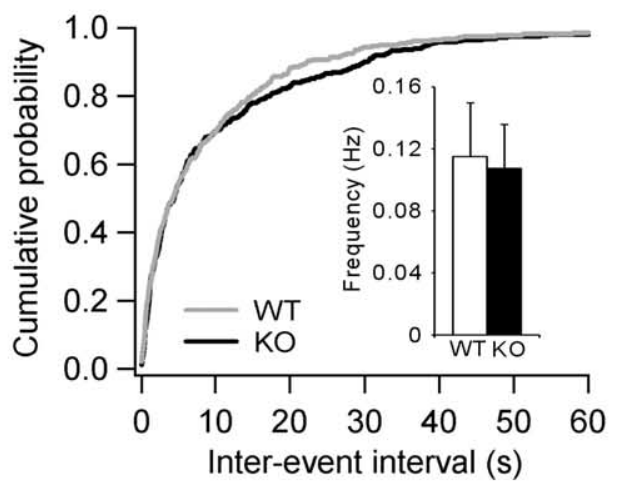

Figure 4. Normal basal synaptic transmission in IRSp53 $3^{-1-}$ mice. A, Normal basal transmission at IRSp53 ${ }^{-1-}$ SC-CA1 synapses. The input- output relationship of basal synaptic transmission was determined by plotting the slopes of fEPSPs against fiber volley amplitudes. The insets show sample traces of fEPSPs. Data represent mean \pm SEM ( $n=60-62$ slices from $10-11$ mice, $4-6$ weeks). $\boldsymbol{B}$, Normal paired-pulse facilitation ratio at IRSp53 $3^{-1-}$ SC-CA1 synapses. Facilitation ratios were plotted against interstimulus intervals. The insets show sample traces of fEPSPs. Mean \pm SEM ( $n=13$ slices from 4 mice for both WT and KO mice, $5-8$ weeks). C $-\boldsymbol{E}$, Normal amplitude and frequency of mEPSCs. Bar graph represents mean \pm SEM [amplitude, WT, 26.89 $\pm 1.47 ; \mathrm{KO}$, $29.06 \pm 1.63 \mathrm{pA}$; frequency, WT, $0.115 \pm 0.034 ; \mathrm{K} 0,0.107 \pm 0.028 \mathrm{~Hz} ; n=17-18$ cells from 3 mice at postnatal day 16 (P16)-P21].

AMPA/NMDA ratio experiments, EPSCs were evoked by electrical stimulation of axons in stratum radiatum at a frequency of $0.05 \mathrm{~Hz}$ with broken glass pipette $(0.3 \sim 0.5 \mathrm{M} \Omega)$ filled with ACSF, and $30 \sim 40$ consecutive traces were averaged to obtain mean current trace. AMPA receptormediated EPSCs were recorded at a holding potential of $-70 \mathrm{mV}$ with the same pipette solution as for mEPSC recording, and picrotoxin (100 $\mu \mathrm{M})$ was added to ACSF to inhibit IPSCs. After recording AMPA receptor-mediated currents, NBQX $(10 \mu \mathrm{M})$ was added to ACSF and holding potential was changed to $+40 \mathrm{mV}$ to record NMDA receptormediated EPSCs. The AMPA/NMDA ratio was calculated by the peak amplitude of mean traces. The slopes of AMPA receptor- or NMDA receptor-mediated currents were calculated by the linear fits of rising phases of EPSCs. To calculate decay kinetics of AMPAR- or NMDARmediated currents, the decay phase of evoked EPSC (eEPSC) was fitted with a double exponential function. Data were acquired by Clampex 9.2 (Molecular Devices) and analyzed by using custom macros written in Igor (Wavemetrics). For field EPSP (fEPSP) recordings, baseline responses were collected at $0.07 \mathrm{~Hz}$ with a stimulation intensity that yielded a half-maximal response. LTP in 4- to 6-week-old hippocampus was induced by four episodes of theta burst stimulation (TBS) with $10 \mathrm{~s}$ intervals. TBS consisted of 10 stimulus trains delivered at $5 \mathrm{~Hz}$; each train consisted of four pulses at $100 \mathrm{~Hz}$. Long-term depression (LTD) was induced in 3- to 4-week-old hippocampal slices with 900 paired-pulse stimulation (40 ms apart) delivered at $1 \mathrm{~Hz}$. Average responses ( \pm SEM) are expressed as percentage of baseline response (at least $10 \mathrm{~min}$ of stable responses). To obtain the ratio of AMPA and NMDA receptor-mediated fEPSPs, $\mathrm{MgCl}_{2}$ in ACSF was reduced to $0.1 \mathrm{~mm}$. NMDA fEPSPs were isolated by the addition of NBQX $(10 \mu \mathrm{M})$. The experimenters were blind to the genotypes of the mice.

Morris water maze. The water maze apparatus consisted of a circular white plastic pool ( $100 \mathrm{~cm}$ diameter; $93 \mathrm{~cm}$ height) filled with water at $24-25^{\circ} \mathrm{C}$. IRSp53 male littermates at 2-6 months were trained to find the hidden platform ( $10 \mathrm{~cm}$ diameter) for two successive trials per day. Animals that did not find the platform within $60 \mathrm{~s}$ were manually guided to the platform. All animals were allowed to remain on the platform for $30 \mathrm{~s}$. Probe test was performed at $1 \mathrm{~d}$ after the last training. Animals were released to the opposite site of the platform and allowed to swim for $60 \mathrm{~s}$ in the absence of platform. Time spent in each quadrant was analyzed using the Noldus EthoVision software (Noldus Information Technology).

Novel object recognition. Mice at 2-6 months of age were habituated in the apparatus (without objects) for $40 \mathrm{~min}$ a day before training session. During training, mice were presented with two different objects for $10 \mathrm{~min}$. Object recognition was scored by the amount of time spent for each object, with the nose of the mouse directed to and located within $2 \mathrm{~cm}$ from the object. Twenty-four hours after the training, one of the blocks was replaced with a new one. Then, trained mice were allowed to explore these blocks for $10 \mathrm{~min}$. All objects were pretested using C57BL/6 WT mice to confirm that there is no specific object preference found in this strain.

\section{Results}

Generation and characterization of IRSp53 $3^{-/-}$mice IRSp $53^{-/-}$mice were generated from a gene-trapped embryonic stem cell line. The site of the gene trap insertion was located in the 
A
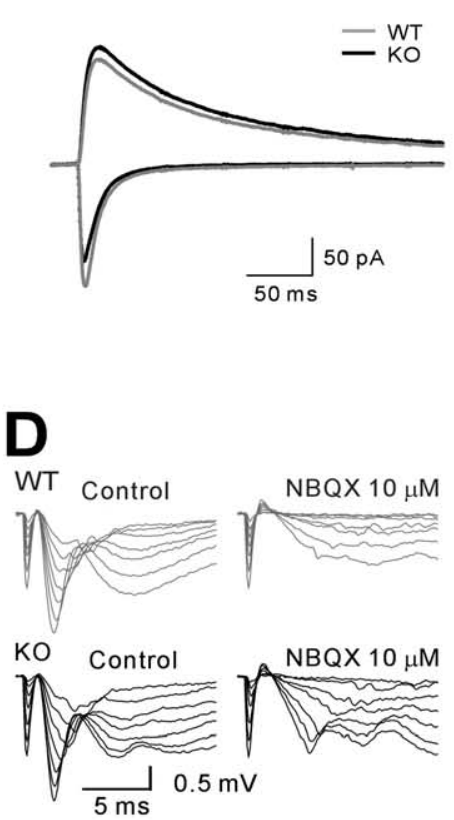

$\mathbf{F}$
B

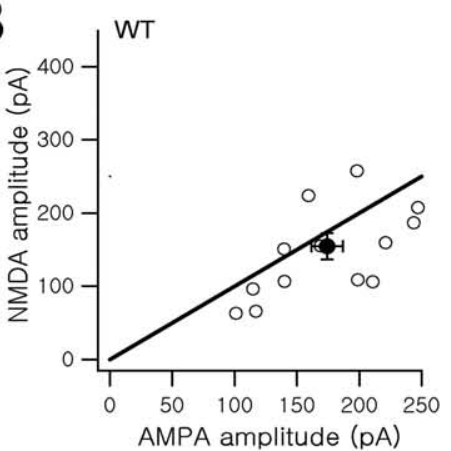

C

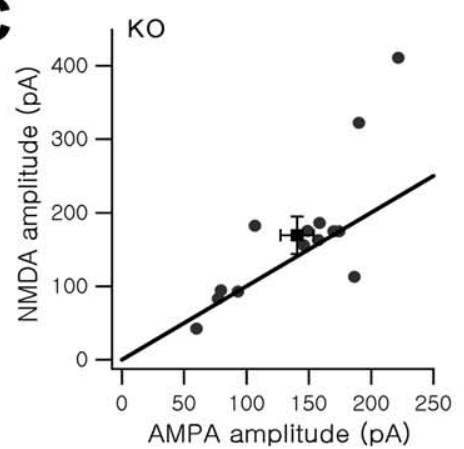

E
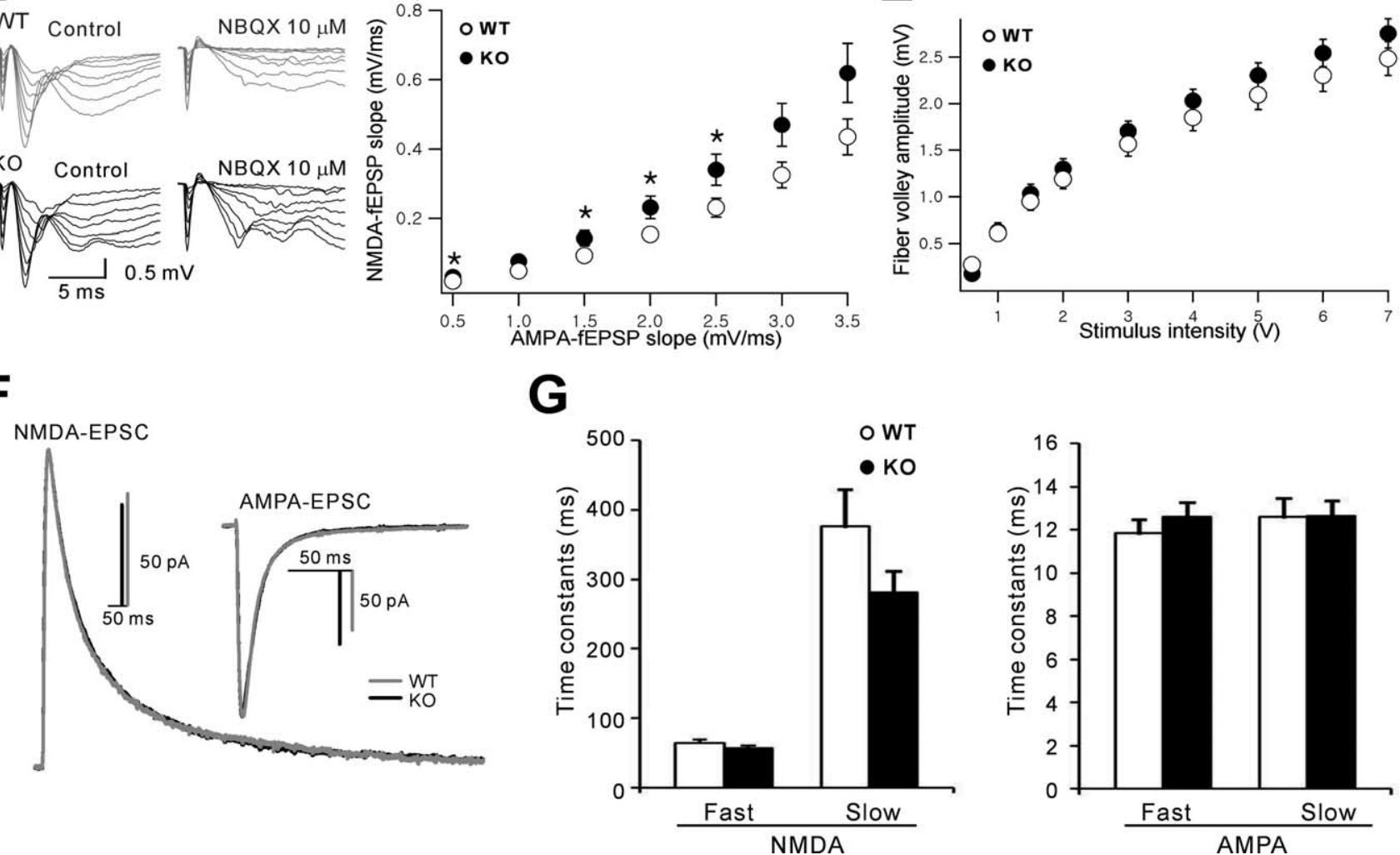

Figure 5. Reduced AMPA/NMDA ratio of excitatory transmission in IRSp53 ${ }^{-1-}$ mice. $A-C$, Decreased AMPA/NMDA ratio of eEPSCs at IRSp53 $3^{-1-}$ SC-CA1 synapses, compared with WT mice. $A$, Mean eEPSC traces mediated by AMPAR (downward) and NMDAR (upward) recorded at holding potentials of -70 and $+40 \mathrm{mV}$, respectively. The gray and black lines indicate current traces from WT and KO mice, respectively. Amplitudes of AMPA and NMDA receptor-mediated EPSCs from WT and KO neurons were plotted for comparison in $\boldsymbol{B}$ and $\boldsymbol{C}$. Each open or gray symbol represents a pair of recordings. The filled circle or square represents mean \pm SEM. D, Reduced AMPA/NMDA ratio of fEPSP slopes at IRSp53 ${ }^{-1-}$ SC-CA1 synapses, compared with WT mice. Sample traces of fEPSPs in the absence and presence of NBQX (an AMPA receptor antagonist) are shown (left). Summary of AMPAR-and NMDAR-mediated fEPSP slopes (right, $n=18$ slices from 6 mice for WT and 17 slices from 6 mice for KO; $5-8$ weeks; ${ }^{*} p<0.05$, Student's $t$ test). $\boldsymbol{E}$, Normal fiber volley amplitudes against stimulation intensities in IRSp53 ${ }^{-I-}$ Schaffer collaterals, measured by field recordings. $\boldsymbol{F}, \boldsymbol{G}$, Normal decay kinetics of NMDA receptor eEPSCS. $\boldsymbol{F}$, AMPAR- and NMDAR-mediated eEPSCs shown in $\boldsymbol{A}$ were scaled to the same maximum for comparison of decay phases (WT, gray; K0, black). $\boldsymbol{G}$, Fast and slow decay kinetics of NMDA receptor eEPSCs was not significantly different between WT and KO mice. The decay kinetics of AMPA receptor eEPSCs was analyzed in parallel for control.

intron between the third and fourth exons, at a site between nucleotides 217 and 218 in the 20,545-nt-long intron. Gene trap at this position led the truncation of the IRSp53 protein ( 522 aa) between amino acids 72 and 73 (Fig. $1 A$ ). The IRSp53 transgene containing the gene trap cassette could be identified by PCR, 884 and $1197 \mathrm{bp}$ for WT and transgene genes, respectively (Fig. $1 B$ ). Birth of IRSp53 $3^{-1-}$ mice did not follow Mendelian ratios, with $10.3 \%$ of progenies being homozygous knock-outs (KOs). IRSp53 $3^{-1-}$ mice exhibited normal body size and no apparent abnormalities in behaviors. In immunoblot analysis, IRSp53 ${ }^{-1-}$ showed no detectable expression of IRSp53 proteins in the brain, whereas IRSp53 $3^{+/-}$showed intermediate levels of protein expression (Fig. 1C). IRSp53 $3^{-/-}$mice did not show changes in the expression levels of other synaptic proteins including IRSp53interacting proteins (PSD-95, Mena, and Eps8) in whole brain and hippocampal extracts (Fig. 1D). The gross morphology of brain sections from IRSp53 $3^{-1-}$ mice was indistinguishable from that of WT mice, as determined by Nissl staining (Fig. 1E).

\section{Expression patterns of IRSp53- $\boldsymbol{\beta}$-geo proteins}

The gene trap in IRSp $53^{-/-}$mice led to the generation of a fusion protein containing the first 72 aa of IRSp53 and $\beta$-geo (a fusion of $\beta$-galactosidase and neomycin phosphotransferase). IRSp53- $\beta$ geo fusion proteins were most strongly detected in brain regions including the hippocampus, cortex, striatum, and cerebellum (Purkinje cells) (Fig. 2), consistent with the strong expression of 
A
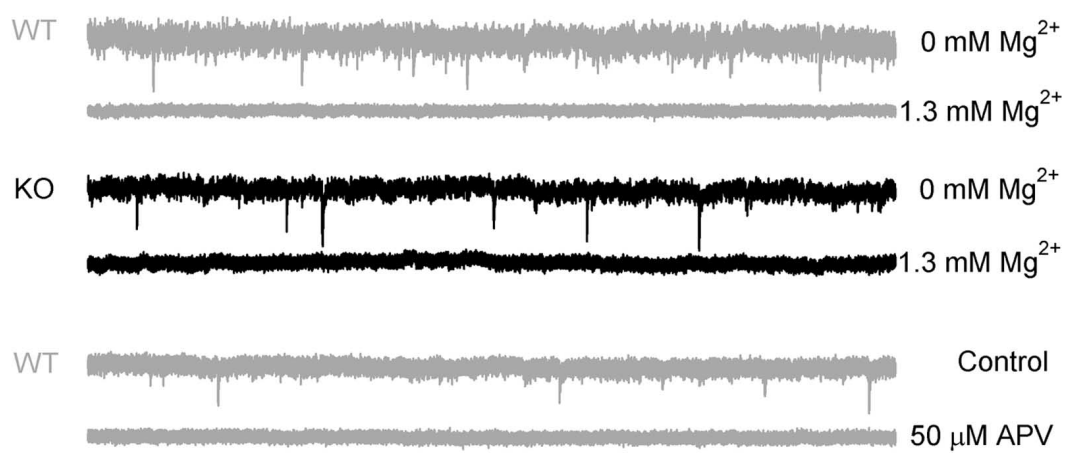

KO

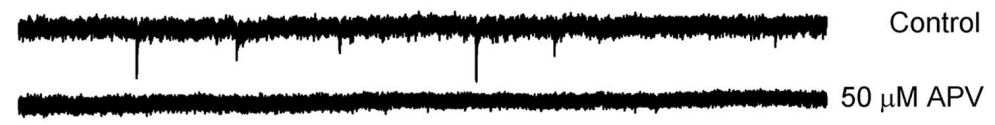

B

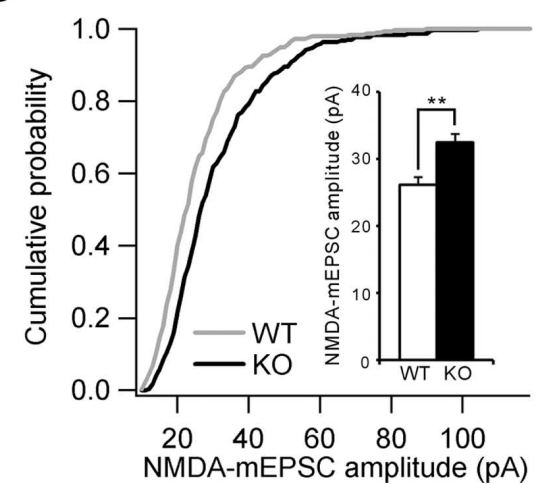

C

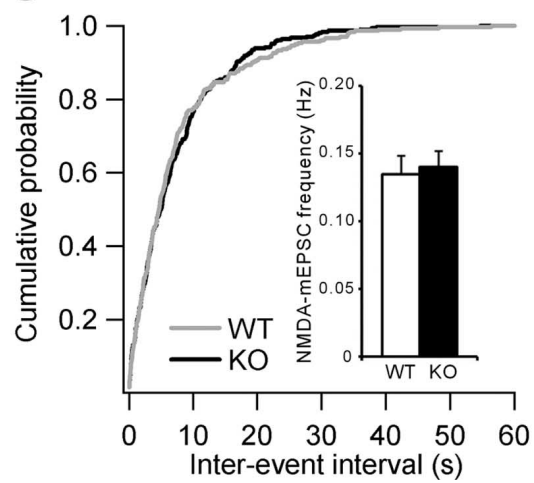

Figure 6. Enhanced NMDA receptor-mediated synaptic transmission in IRSp53 ${ }^{-1-}$ mice. $\boldsymbol{A}-\boldsymbol{C}$, Sample traces $(\boldsymbol{A})$ showing that the amplitude $(\boldsymbol{B})$, but not frequency $(\boldsymbol{C})$, of NMDA receptor-mediated mEPSC is enhanced at IRSp53 ${ }^{-/-}$SC-CA1 synapses. In control recordings, NMDA receptor mEPSCs were abolished in the presence of $1.3 \mathrm{~mm} \mathrm{Mg}^{2+}$ and $50 \mu \mathrm{M}$ APV (an NMDA receptor antagonist). Bar graph represents mean \pm SEM (amplitude, WT, $26.14 \pm 1.20 ; \mathrm{KO}, 32.43 \pm 1.28 \mathrm{pA}$; frequency, WT, $0.13 \pm$ $0.01 ; \mathrm{K} 0,0.14 \pm 0.01 \mathrm{~Hz} ; n=15$ cells from 3 mice at P21-P27; ${ }^{* *} p<0.01$, Student's $t$ test).

IRSp53 mRNAs in these regions of mouse and rat brains, determined by in situ hybridization (Thomas et al., 2001; Bockmann et al., 2002). In the hippocampus, the strongest expression was detected in CA1 pyramidal neurons, with weaker expression in the dentate gyrus and the CA3 region (Fig. $2 D$ ). In the cerebellum, IRSp53- $\beta$-geo expression was mainly observed in Purkinje cells (Fig. 2 F).

Normal spine density and synaptic ultrastructures in IRSp53 $3^{-l-}$ mice

IRSp53 has been implicated in the regulation of spine density (Choi et al., 2005). We, thus, observed the density and ultrastructural morphologies of dendritic spines in IRSp53 $3^{-1-}$ mice by electron microscopic analysis. Dendritic spines in the apical dendrites of CA1 pyramidal neurons were analyzed. Unexpectedly, the total number of dendritic spines was not significantly changed in IRSp53 $3^{-1-}$ mice compared with WT mice (WT, $590 \pm 24$ spines $/ 1000 \mu \mathrm{m}^{2} ; \mathrm{KO}, 554 \pm 29$ spines $/ 1000 \mu \mathrm{m}^{2}$ ) (Fig. $3 A, B)$. In addition, the number of perforated spines, which have partitioned PSDs and are thought to represent mature excitatory synapses (Calverley and Jones, 1990; Geinisman et al., 1991), was unchanged in IRSp53 ${ }^{-1-}$ mice (WT, $35.0 \pm 6.4 / 1000 \mu \mathrm{m}^{2}$; KO, $25.0 \pm 2.7$ ) (Fig. $3 B$ ). There were no significant changes in the area of spine heads (total, normal, and perforated) (total, WT,
$20 \mathrm{pA}$

$0.07 \pm 0.009 \mu \mathrm{m}^{2} ; \mathrm{KO}, 0.07 \pm 0.006$; nor$\mathrm{mal}, \mathrm{WT}, 0.07 \pm 0.007 ; \mathrm{KO}, 0.07 \pm 0.003$; perforated, WT, $0.18 \pm 0.022 ; \mathrm{KO}, 0.15 \pm$ 0.023 ) (Fig. 3C). In addition, the length of the PSD was unchanged in IRSp $53^{-1-}$ mice (WT, $0.20 \pm 0.006 \mu \mathrm{m}$; KO, $0.19 \pm$ $0.003 \mu \mathrm{m}$; spine number analyzed, 1648 for WT and 1535 for KO; $n=3$ mice). These results suggest that deficiency of IRSp53 in mice does not cause significant changes in spine density and ultrastructure.

Normal basal synaptic transmission in IRSp53 $3^{-1-}$ mice

IRSp53 binds and bundles actin filaments (Yamagishi et al., 2004) and interacts with various actin-regulatory proteins. The actin cytoskeleton in dendritic spines is implicated in the regulation of synaptic transmission and plasticity (Hayashi and Majewska, 2005; Tada and Sheng, 2006; Cingolani and Goda, 2008). We, thus, measured excitatory synaptic transmissions by extracellular recordings at Schaffer collateral-CA1 pyramidal (SC-CA1) synapses of IRSp53 ${ }^{-/-}$mice. The ratio of fEPSP slope to stimulus intensity (inputoutput ratio) of synaptic transmission was not changed in IRSp53 $53^{-1-}$ mice, compared with WT mice (Fig. 4A), suggesting that basal synaptic transmission has not been changed by IRSp53 deficiency.

Presynaptic characteristics at SC-CA1 synapses were determined by measuring paired-pulse facilitation (PPF), the ratio of initial slopes of fEPSPs to two consecutive presynaptic stimuli with different time intervals. PPF was not significantly changed in IRSp53 $3^{-/-}$synapses (Fig. $4 B$ ), suggesting that the probability of presynaptic release is not affected by IRSp53 deficiency.

We next tested whether spontaneous synaptic transmission is affected in IRSp53 $3^{-/-}$neurons, by measuring mEPSCs from CA1 pyramidal neurons by whole-cell recordings. Both the amplitude and frequency of mEPSCs in IRSp53 $3^{-1-}$ mice were not changed, compared with those of WT neurons (Fig. $4 C-E$ ). Together, these results suggest that IRSp53 deficiency does not affect evoked and spontaneous AMPA receptor-mediated synaptic transmission.

\section{Reduced AMPA/NMDA ratio of excitatory transmission in IRSp53 $3^{-1-}$ mice}

We next compared the ratio of AMPA receptor- and NMDA receptor-mediated evoked EPSCs (the AMPA/NMDA ratio of eEPSCs) through whole-cell recordings. Interestingly, the AMPA/NMDA ratio of eEPSCs at SC-CA1 synapses was significantly decreased $(\sim 26 \%)$ in IRSp53 $3^{-1-}$ mice compared with WT mice (WT, $1.27 \pm 0.11 ; \mathrm{KO}, 0.94 \pm 0.08 ; n=14$ cells from $5 \sim 6$ mice at 3-4 weeks; $p<0.05$, Student's $t$ test) (Fig. $5 A-C$ ), suggesting that IRSp53 is required to maintain the normal ratio of AMPA and NMDA receptor-mediated synaptic transmission.

In addition, we measured the AMPA/NMDA ratio of fEPSP slopes by extracellular recordings. We observed a similar decrease in 
the AMPA/NMDA ratio in IRSp53 $3^{-1-}$ SC-CA1 synapses (Fig. 5D). The amplitudes of presynaptic fiber volleys induced by different stimulus intensities in Schaffer collaterals were not changed in IRSp53 $3^{-1-}$ slices (Fig. 5E), suggesting that electrophysiological properties of the presynaptic fibers have not been changed.

The reduced AMPA/NMDA ratio of eEPSCs, in combination with normal basal transmission, which is mainly mediated by AMPA receptors, suggests that NMDA receptor-mediated transmission has been increased. A possible mechanism for an enhancement in NMDA receptor function is an alteration in subunit composition (i.e., NR2B-containing NMDA receptors have slower decay kinetics and mediate a greater amount of currents) (Vicini et al., 1998; Cull-Candy and Leszkiewicz, 2004). The decay of NMDA receptor eEPSCs, obtained from the experiments described in Figure $5 A-C$, were best fitted to a double exponential decay (Fig. $5 F, G$ ). However, there was no significant difference in both fast and slow decay time constants in IRSp $53^{-1-}$ neurons, compared with WT mice (fast: WT, $63.9 \pm 4.6 \mathrm{~ms}$; KO, $56.3 \pm 3.9 ; n=14 ; p=0.23$; slow: $\mathrm{WT}, 375.8 \pm 53.5 ; \mathrm{KO}, 280.2 \pm$ $31.8 ; n=14 ; p=0.14)$. In control analysis, fast and slow decay kinetics of AMPA receptor eEPSCs was unchanged. These results suggest that the decay kinetics of NMDA receptor eEPSCs has not been changed by IRSp53 deficiency.

\section{Enhanced NMDA receptor-mediated transmission in IRSp53 ${ }^{-1-}$ mice}

To test whether IRSp53 deficiency causes changes in NMDA receptor-mediated transmission, we measured NMDA receptor mEPSCs in the presence of NBQX (an AMPA receptor antagonist) in magnesium-free extracellular solution. The amplitude, but not the frequency, of NMDA mEPSCs was significantly increased at IRSp $53^{-1-}$ SC-CA1 synapses (Fig. 6A,B). In control experiments, NMDA receptor mEPSCs were abolished in the presence of $1.3 \mathrm{~mm}$ $\mathrm{Mg}^{2+}$ or APV (an NMDA receptor antagonist) (Fig. 6A). These results suggest that IRSp53 is required for the maintenance of normal NMDA receptor-mediated transmission.

\section{Enhanced LTP in IRSp53 ${ }^{-/-}$mice}

We next tested whether IRSp $53^{-/-}$deficiency causes any changes in synaptic plasticity, by measuring LTP and LTD in the CA1 region of hippocampus. When LTP was induced by TBS at SC-CA1 synapses, IRSp53 $3^{-1-}$ slices showed a marked increase $(\sim 68 \%)$ in the magnitude of LTP $(169.3 \pm 7.0 \%$ of baseline during the last 10 min of the recording; $\left.n=22 ;{ }^{*} p<0.05\right)$, compared with WT mice $(141.0 \pm 4.7 \%$ of baseline; $n=23)$ (Fig. 7A). In contrast, LTD in IRSp $53^{-1-}$ slices, induced by paired-pulse low frequency stimulation, was not significantly different from that of WT mice (KO, $64.7 \pm 6.5 \%$ of baseline, $n=11$; WT, $64.8 \pm 7.5$ of baseline, $n=16$; $p=0.99$ ) (Fig. $7 B$ ). These results suggest that the deficiency of IRSp53 leads to selective enhancement of LTP.

\section{Enhanced NMDA receptor-mediated transmission by theta burst stimulation}

The increase in TBS-induced LTP in IRSp53 $3^{-1-}$ hippocampal slices (Fig. 7) may be attributable to enhanced NMDA receptormediated transmission. To test this hypothesis, we measured NMDA receptor transmission during TBS. The cumulative slopes of NMDA receptor-mediated EPSCs (NMDA-EPSCs) during TBS, normalized to baseline slopes of AMPA-EPSCs, were significantly increased in IRSp $53^{-1-}$ SC-CA1 synapses, compared with WT slices (Fig. 8A-C). These results suggest that NMDAR-mediated transmission was enhanced during TBS. In contrast, the cumulative slopes of NMDA-EPSCs, normalized to
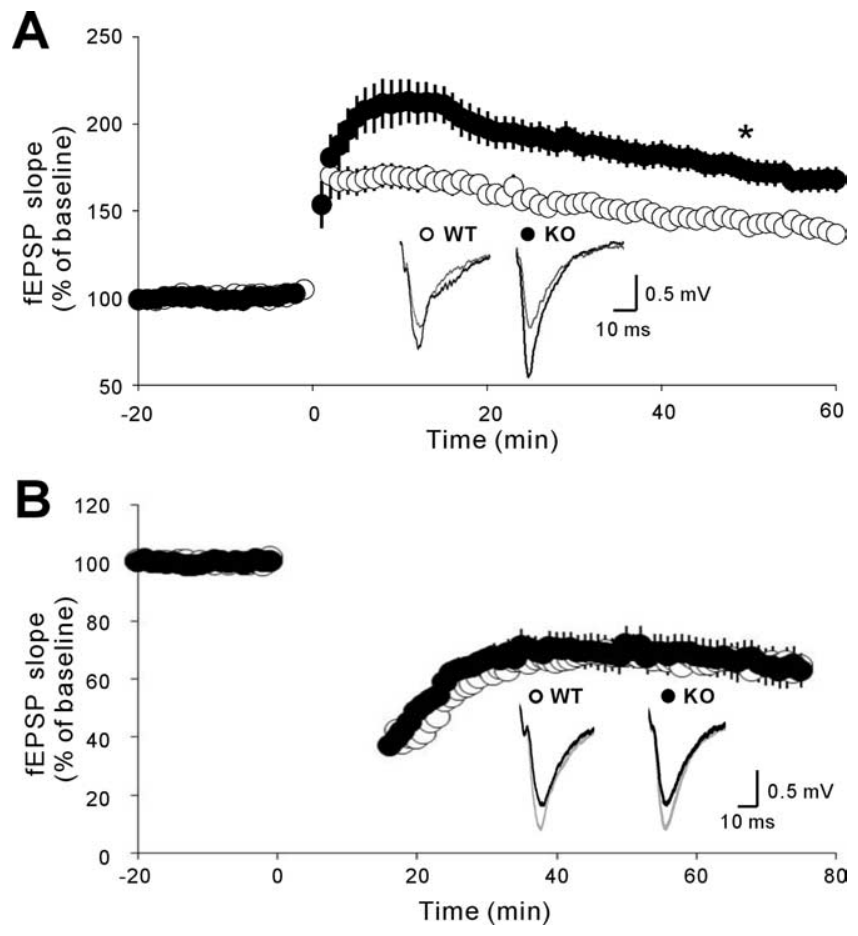

Figure 7. Selective enhancement of LTP at IRSp53 ${ }^{-1-} \mathrm{SC}-\mathrm{CA} 1$ synapses. $A$, Enhanced LTP. LTP was induced by theta burst stimulation. Shown is mean \pm SEM $(n=22-23$ slices from 13-14 mice). The gray and black traces were taken at 0 min and at the end of recording, respectively. ${ }^{*} p<0.001$ compared to baseline. $\boldsymbol{B}$, Unchanged LTD. LTD was induced by pairedpulse low frequency stimulation (900 paired pulses at $1 \mathrm{~Hz}$; interstimulus interval, $40 \mathrm{~ms}$ ). Shown is mean \pm SEM ( $n=9-14$ slices from 7 mice). Calibration: $10 \mathrm{~ms}, 0.5 \mathrm{mV}$.

baseline NMDA-EPSC slopes, were unchanged in IRSp53-1slices (Fig. $8 D$ ), suggesting that the enhanced NMDA transmission in IRSp53 $3^{-1-}$ slices is unlikely to be caused by enhanced presynaptic release.

In the experiments described in Figure $8 A-D$, we analyzed the initial slopes of the rising phases, rather than peak amplitudes, of NMDA- or AMPA-EPSCs because NMDA-EPSCs did not reach peak amplitudes during the short interstimulus intervals $(10 \mathrm{~ms})$ of TBS. However, supporting that EPSC slopes reliably represent EPSC amplitudes, the initial slopes of baseline NMDA- or AMPA-EPSCs correlated well with their peak amplitudes in both WT and IRSp53 $3^{-1-}$ slices (Fig. 8E,F). Moreover, similar levels of paired-pulse facilitations were observed when NMDA-EPSCs were analyzed by EPSC slopes and amplitudes (Fig. 8G). The AMPA/NMDA ratio of excitatory transmission based on EPSC slopes was reduced at IRSp53 $3^{-1-}$ SC-CA1 synapses (Fig. $8 H$ ), similar to the results based on the analysis of EPSC amplitudes (Fig. 5A-D). Together, these results indicate NMDA receptormediated transmission is enhanced by IRSp 53 deficiency.

\section{Impaired spatial learning and novel object recognition in} IRSp $53^{-/-}$mice

The selective enhancement of LTP in the IRSp53 ${ }^{-/-}$hippocampal CA1 region suggests that IRSp53 $3^{-1-}$ mice may have impaired learning and memory. In the hidden-platform Morris water maze test, IRSp $53^{-1-}$ mice showed decreased spatial learning during the training period, as indicated by significantly increased escape latencies, compared with WT mice (Fig. 9A). In the probe test, in which the hidden platform was removed, IRSp $53^{-l-}$ mice spent a significantly reduced amount of time in the target quadrant (Fig. 9B). The swimming speed of IRSp53 $3^{-1-}$ mice was compa- 
A

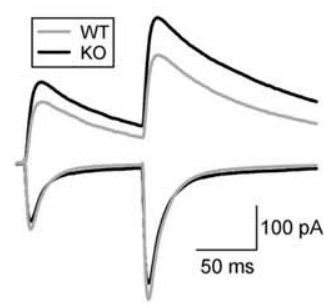

B

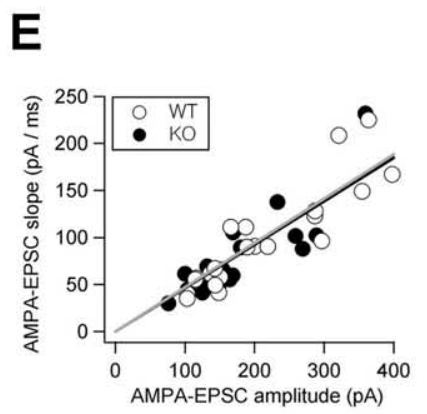

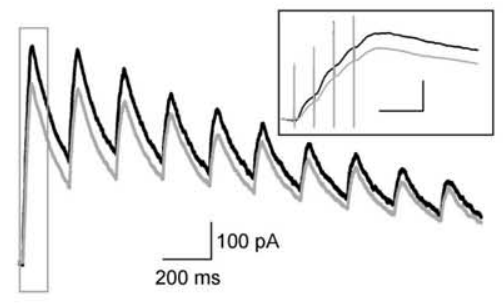

$\mathbf{F}$

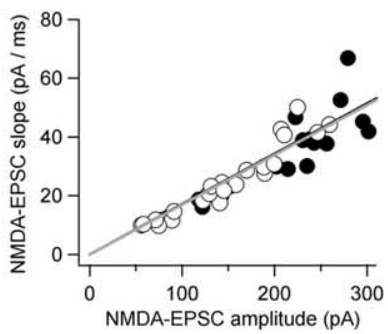

C

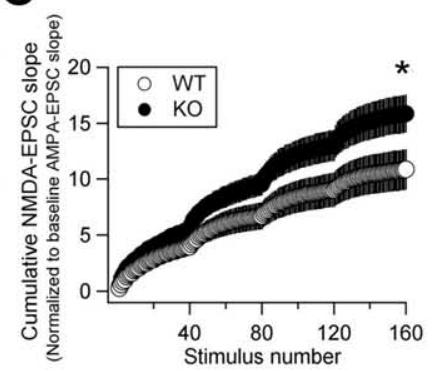

G

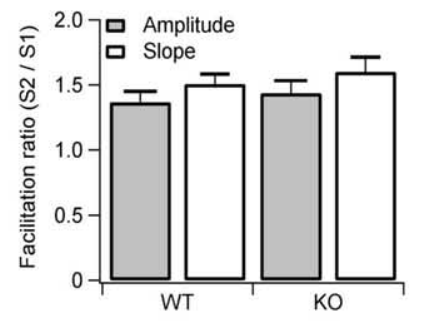

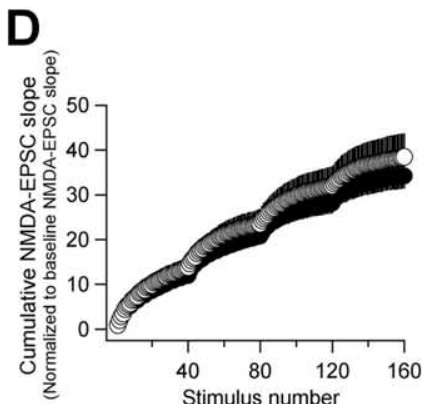

H

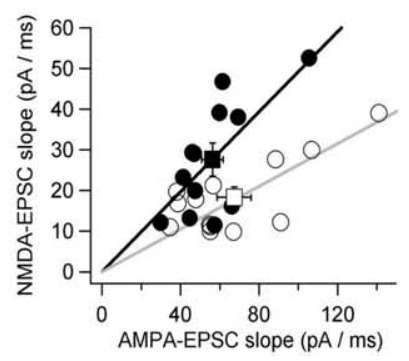

Figure 8. Enhanced NMDA receptor-mediated synaptic transmission during the delivery of TBS. $A$, Mean traces of baseline AMPA-EPSCs and NMDA-EPSCS. Baseline AMPA-EPSCs and NMDA-EPSCs were induced by paired-pulse stimulation (100 ms apart) at the holding potentials of -70 and $+40 \mathrm{mV}$, respectively. $\boldsymbol{B}$, Mean traces of NMDA-EPSCs during the first episode (10 stimulus trains) of TBS. The inset shows NMDA-EPSCs during the first train of TBS (boxed). Calibration (inset): $20 \mathrm{~ms}, 200 \mathrm{pA}$. C, Enhanced NMDA-EPSCs during TBS. Cumulative NMDA-EPSCS during TBS were normalized to baseline AMPA-EPSCs. $n=13$ cells for WT and 12 for KO from 6 mice; ${ }^{*} p<0.05$ compared to WT, Student's $t$ test. D, NMDA-EPSCs during TBS are not changed when normalized to baseline NMDA-EPSCS. E, AMPA-EPSC slopes correlate well with AMPA-EPSC amplitudes. $\boldsymbol{F}$, NMDA-EPSC slopes correlate well with NMDA-EPSC amplitudes. $\boldsymbol{G}$, Similar levels of paired-pulse facilitations are observed when NMDA-EPSCs are analyzed by EPSC slopes and amplitudes. Error bars indicate SEM. $\boldsymbol{H}$, The ratio of AMPA/NMDA transmission is reduced in IRSp53 ${ }^{-1-}$ mice when analyzed by EPSC slopes.

rable with that of WT mice $(\mathrm{WT}, 23.1 \pm 0.2 \mathrm{~cm} / \mathrm{s}$; KO, $20.6 \pm$ 2.7).

Novel object recognition is known to require hippocampusdependent memory (Myhrer, 1988; Reed and Squire, 1997). During training, mice were presented with two different objects (objects A and B) for $10 \mathrm{~min}$. Both WT and IRSp53 ${ }^{-1-}$ mice showed similar preference for the two objects (Fig. 9C), suggesting that they have similar levels of visual perception, attention, and motivation. Twenty-four hours after the training, the mice were allowed to explore the objects, with one of the two objects (object B) replaced with a new one (object C). IRSp53 $3^{-1-}$ mice showed a similar preference for the two objects $(48.0 \pm 1.9$ and $52.0 \pm$ $1.9 \%$ for objects A and C, respectively), whereas WT mice showed a significantly higher preference for the new object $(39.4 \pm 2.4$ and $60.6 \pm 2.4 \%$ for A and C, respectively) (Fig. 9D). Together, these behavioral results suggest that IRSp53 ${ }^{-I-}$ mice have impairments in hippocampus-dependent learning and memory.

\section{Discussion}

\section{Regulation of dendritic spines by IRSp53}

Our previous results have implicated IRSp53 in the regulation of dendritic spine density and morphology (Choi et al., 2005). IRSp53 overexpression in cultured hippocampal neurons increases spine density in a manner requiring the $\mathrm{C}$ terminus and SH3 domains, which binds PSD-95 and various actin-regulatory proteins, respectively. In contrast, acute knockdown of IRSp53, or dominant-negative inhibition of IRSp53, decreases both the density and size of dendritic spines. Based on these results, we expected changes in the density or morphology of dendritic spines in IRSp53 $3^{-1-}$ neurons. However, we could not observe any significant changes in the number or ultrastructural properties of dendritic spines. Whether this finding is attributable to developmental compensation remains to be determined.

\section{Regulation of NMDA receptor-mediated transmission by IRSp53}

Our whole-cell and extracellular recording results indicate a significant decrease in the AMPA/NMDA ratio of excitatory synaptic transmission at IRSp53 $3^{-/-}$SC-CA1 synapses (Fig. 5). In addition, NMDA receptor-mediated transmission was significantly increased at IRSp53 $3^{-1-}$ SC-CA1 synapses (Fig. 6), whereas AMPA receptor-mediated transmissions were normal (Fig. 4). These results suggest that IRSp53 is required for the maintenance of NMDA receptor-mediated transmission.

Because IRSp53 ${ }^{-1-}$ at SC-CA1 synapses exhibit normal decay kinetics of NMDA receptor eEPSCs, it is unlikely that changes in the particular subunit of NMDA receptors is responsible for the enhancement of NMDA transmission. Alternatively, there might be an increase in the synaptic content of NMDA receptors or in the functional properties of NMDA receptors (i.e., through receptor phosphorylation). Of note, genetic ablation of Eps8, a direct binding partner of IRSp53, enhances NMDA receptor responses through increases in the amplitude and decay kinetics of NMDA currents (Offenhäuser et al., 2006). It is possible that IRSp53 and Eps8 may act in concert to regulate NMDA receptor responses, although the expression levels of Eps8 were not changed in IRSp $53^{-/-}$mice.

\section{Regulation of LTP and learning and memory behaviors by IRSp53}

IRSp53 deficiency leads to a marked increase in LTP at Schaffer collateral-CA1 pyramidal synapses, with no changes in LTD. 
What might be the underlying mechanisms? Our data indicate that NMDA receptor-mediated transmission was increased during the delivery of TBS (Fig. 8), which were used to induce LTP. This might be responsible for the enhanced LTP, considering the pivotal role for NMDA receptors in LTP regulation (Malenka and Bear, 2004).

In Morris water maze assays, IRSp53 ${ }^{-/-}$mice show impaired spatial learning during training as well as reduced target quadrant occupancy during the probe test. In object recognition assays, IRSp53 $3^{-1-}$ mice show reduced recognition of the new object. These results suggest that IRSp53 is important for both spatial and object learning and memory. In addition, in view of the selective enhancement of LTP in IRSp53 $3^{-1-}$ mice, excessive LTP in the CA1 region appears to have negative influences on hippocampusdependent forms of learning and memory.

IRSp53 directly interacts with PSD-95 (Soltau et al., 2002; Choi et al., 2005). Transgenic mice carrying a truncated version of PSD-95 exhibit enhanced LTP and impaired spatial learning (Migaud et al., 1998), similar to IRSp53 ${ }^{-1-}$ mice. Because both IRSp53 and PSD-95 are abundantly expressed in the brain (Cheng et al., 2006), it is likely that these two proteins may have a significant functional association. It is therefore possible that IRSp53 is responsible, at least in part, for the plasticity and behavioral phenotypes observed in PSD95-deficient mice.

In conclusion, our study identifies novel involvements of IRSp53 in the regulation of NMDA receptor-mediated synaptic transmission, LTP (but not LTD), and learning and memory behaviors, in addition to its known roles in neurite growth and spine morphogenesis.

\section{References}

Abbott MA, Wells DG, Fallon JR (1999) The insulin receptor tyrosine kinase substrate p58/53 and the insulin receptor are components of CNS synapses. J Neurosci 19:7300-7308.

Abou-Kheir W, Isaac B, Yamaguchi H, Cox D (2008) Membrane targeting of WAVE2 is not sufficient for WAVE2-dependent actin polymerization: a role for IRSp53 in mediating the interaction between Rac and WAVE2. J Cell Sci 121:379-390.

Bockmann J, Kreutz MR, Gundelfinger ED, Böckers TM (2002) ProSAP/ Shank postsynaptic density proteins interact with insulin receptor tyrosine kinase substrate IRSp53. J Neurochem 83:1013-1017.

Calverley RK, Jones DG (1990) Contributions of dendritic spines and perforated synapses to synaptic plasticity. Brain Res Brain Res Rev 15:215-249.

Cheng D, Hoogenraad CC, Rush J, Ramm E, Schlager MA, Duong DM, Xu P, Wijayawardana SR, Hanfelt J, Nakagawa T, Sheng M, Peng J (2006) Relative and absolute quantification of postsynaptic density proteome isolated from rat forebrain and cerebellum. Mol Cell Proteomics 5:1158-1170.

Choi J, Ko J, Racz B, Burette A, Lee JR, Kim S, Na M, Lee HW, Kim K, Weinberg RJ, Kim E (2005) Regulation of dendritic spine morphogenesis by insulin receptor substrate 53, a downstream effector of Rac1 and Cdc42 small GTPases. J Neurosci 25:869-879.
Cingolani LA, Goda Y (2008) Actin in action: the interplay between the actin cytoskeleton and synaptic efficacy. Nat Rev Neurosci 9:344-356.

Craig AM, Kang Y (2007) Neurexin-neuroligin signaling in synapse development. Curr Opin Neurobiol 17:43-52.

Cull-Candy SG, Leszkiewicz DN (2004) Role of distinct NMDA receptor subtypes at central synapses. Sci STKE 2004:re16.

Disanza A, Mantoani S, Hertzog M, Gerboth S, Frittoli E, Steffen A, Berhoerster K, Kreienkamp HJ, Milanesi F, Di Fiore PP, Ciliberto A, Stradal TE, Scita G (2006) Regulation of cell shape by Cdc42 is mediated by the synergic actin-bundling activity of the Eps8-IRSp53 complex. Nat Cell Biol 8:1337-1347.

Funke L, Dakoji S, Bredt DS (2005) Membrane-associated guanylate kinases regulate adhesion and plasticity at cell junctions. Annu Rev Biochem 74:219-245.

Geinisman Y, deToledo-Morrell L, Morrell F (1991) Induction of long-term potentiation is associated with an increase in the number of axospinous synapses with segmented postsynaptic densities. Brain Res 566:77-88.

Govind S, Kozma R, Monfries C, Lim L, Ahmed S (2001) Cdc42Hs facilitates cytoskeletal reorganization and neurite outgrowth by localizing the $58-\mathrm{kD}$ insulin receptor substrate to filamentous actin. J Cell Biol 152:579-594.

Habermann B (2004) The BAR-domain family of proteins: a case of bending and binding? EMBO Rep 5:250-255.

Hayashi Y, Majewska AK (2005) Dendritic spine geometry: functional implication and regulation. Neuron 46:529-532. 
Hori K, Konno D, Maruoka H, Sobue K (2003) MALS is a binding partner of IRSp53 at cell-cell contacts. FEBS Lett 554:30-34.

Hori K, Yasuda H, Konno D, Maruoka H, Tsumoto T, Sobue K (2005) NMDA receptor-dependent synaptic translocation of insulin receptor substrate p53 via protein kinase C signaling. J Neurosci 25:2670-2681.

Kennedy MB (2000) Signal-processing machines at the postsynaptic density. Science 290:750-754.

Krugmann S, Jordens I, Gevaert K, Driessens M, Vandekerckhove J, Hall A (2001) Cdc42 induces filopodia by promoting the formation of an IRSp53:Mena complex. Curr Biol 11:1645-1655.

Lim KB, Bu W, Goh WI, Koh E, Ong SH, Pawson T, Sudhaharan T, Ahmed S (2008) The Cdc42 effector IRSp53 generates filopodia by coupling membrane protrusion with actin dynamics. J Biol Chem 283:20454-20472.

Malenka RC, Bear MF (2004) LTP and LTD: an embarrassment of riches. Neuron 44:5-21.

Mattila PK, Pykäläinen A, Saarikangas J, Paavilainen VO, Vihinen H, Jokitalo E, Lappalainen P (2007) Missing-in-metastasis and IRSp53 deform $\mathrm{PI}(4,5) \mathrm{P} 2$-rich membranes by an inverse BAR domain-like mechanism. J Cell Biol 176:953-964.

Migaud M, Charlesworth P, Dempster M, Webster LC, Watabe AM, Makhinson M, He Y, Ramsay MF, Morris RG, Morrison JH, O'Dell TJ, Grant SG (1998) Enhanced long-term potentiation and impaired learning in mice with mutant postsynaptic density-95 protein. Nature 396:433-439.

Miki H, Yamaguchi H, Suetsugu S, Takenawa T (2000) IRSp53 is an essential intermediate between Rac and WAVE in the regulation of membrane ruffling. Nature 408:732-735.

Millard TH, Bompard G, Heung MY, Dafforn TR, Scott DJ, Machesky LM, Fütterer K (2005) Structural basis of filopodia formation induced by the IRSp53/MIM homology domain of human IRSp53. EMBO J 24:240-250.

Myhrer T (1988) Exploratory behavior and reaction to novelty in rats with hippocampal perforant path systems disrupted. Behav Neurosci 102:356-362.

Nakagawa H, Miki H, Nozumi M, Takenawa T, Miyamoto S, Wehland J, Small JV (2003) IRSp53 is colocalised with WAVE2 at the tips of protruding lamellipodia and filopodia independently of Mena. J Cell Sci 116:2577-2583.

Offenhäuser N, Castelletti D, Mapelli L, Soppo BE, Regondi MC, Rossi P, D’Angelo E, Frassoni C, Amadeo A, Tocchetti A, Pozzi B, Disanza A, Guarnieri D, Betsholtz C, Scita G, Heberlein U, Di Fiore PP (2006) Increased ethanol resistance and consumption in Eps8 knockout mice correlates with altered actin dynamics. Cell 127:213-226.

Okabe S (2007) Molecular anatomy of the postsynaptic density. Mol Cell Neurosci 34:503-518.

Reed JM, Squire LR (1997) Impaired recognition memory in patients with lesions limited to the hippocampal formation. Behav Neurosci 111:667-675.

Scannevin RH, Huganir RL (2000) Postsynaptic organization and regulation of excitatory synapses. Nat Rev Neurosci 1:133-141.

Scita G, Confalonieri S, Lappalainen P, Suetsugu S (2008) IRSp53: crossing the road of membrane and actin dynamics in the formation of membrane protrusions. Trends Cell Biol 18:52-60.

Sekerková G, Loomis PA, Changyaleket B, Zheng L, Eytan R, Chen B, Mugnaini E, Bartles JR (2003) Novel espin actin-bundling proteins are localized to Purkinje cell dendritic spines and bind the Src homology 3 adapter protein insulin receptor substrate p53. J Neurosci 23:1310-1319.

Sheng M, Hoogenraad CC (2007) The postsynaptic architecture of excitatory synapses: a more quantitative view. Annu Rev Biochem 76:823-847.

Sheng M, Cummings J, Roldan LA, Jan YN, Jan LY (1994) Changing subunit composition of heteromeric NMDA receptors during development of rat cortex. Nature 368:144-147.

Soltau M, Richter D, Kreienkamp HJ (2002) The insulin receptor substrate IRSp53 links postsynaptic shank1 to the small G-protein cdc42. Mol Cell Neurosci 21:575-583.

Soltau M, Berhörster K, Kindler S, Buck F, Richter D, Kreienkamp HJ (2004) Insulin receptor substrate of $53 \mathrm{kDa}$ links postsynaptic shank to PSD-95. J Neurochem 90:659-665.

Suetsugu S, Kurisu S, Oikawa T, Yamazaki D, Oda A, Takenawa T (2006a) Optimization of WAVE2 complex-induced actin polymerization by membrane-bound IRSp53, PIP(3), and Rac. J Cell Biol 173:571-585.

Suetsugu S, Murayama K, Sakamoto A, Hanawa-Suetsugu K, Seto A, Oikawa T, Mishima C, Shirouzu M, Takenawa T, Yokoyama S (2006b) The RAC binding domain/IRSp53-MIM homology domain of IRSp53 induces RAC-dependent membrane deformation. J Biol Chem 281:35347-35358.

Tada T, Sheng M (2006) Molecular mechanisms of dendritic spine morphogenesis. Curr Opin Neurobiol 16:95-101.

Thomas EA, Foye PE, Alvarez CE, Usui H, Sutcliffe JG (2001) Insulin receptor substrate protein $\mathrm{p} 53$ localization in rats suggests mechanism for specific polyglutamine neurodegeneration. Neurosci Lett 309:145-148.

Vicini S, Wang JF, Li JH, Zhu WJ, Wang YH, Luo JH, Wolfe BB, Grayson DR (1998) Functional and pharmacological differences between recombinant $N$-methyl-D-aspartate receptors. J Neurophysiol 79:555-566.

Waites CL, Craig AM, Garner CC (2005) Mechanisms of vertebrate synaptogenesis. Annu Rev Neurosci 28:251-274.

Yamagishi A, Masuda M, Ohki T, Onishi H, Mochizuki N (2004) A novel actin bundling/filopodium-forming domain conserved in insulin receptor tyrosine kinase substrate $\mathrm{p} 53$ and missing in metastasis protein. J Biol Chem 279:14929-14936. 